$24 *$ Corresponding author

$25 \&$ These authors contributed equally to this work P.O. Box KB 143, Accra, Ghana, West Africa. Africa. Parkallee 1-40, 23845, Borstel, Germany Burkina Faso.

\title{
Household cockroaches carry CTX-M-15, OXA-48 and NDM-1, and share beta-lactam resistance determinants with humans
}

Noah Obeng-Nkrumah ${ }^{1 \&}$, Appiah-Korang Labi2\&, Harriet Blankson1,1,3*, Georgina AwuahMensah $^{1,3}$, Daniel Oduro-Mensah ${ }^{5}$, Judelove Anum ${ }^{1}$, James Teye ${ }^{1}$, Solomon Dzidzornu Kwashie, ${ }^{1}$ Evariste Bako ${ }^{6}$, Patrick Ferdinand Ayeh-Kumi ${ }^{1}$, Richard Asmah ${ }^{1}$

${ }^{1}$ Department of Medical Laboratory Sciences, School of Biomedical and Allied Health Sciences,

${ }^{2}$ Department of Microbiology, Korle-Bu Teaching Hospital, P.O. Box 77, Accra, Ghana, West

${ }^{3}$ Molecular and Experimental Mycobacteriology, Research Centre Bostel, Leibniz Lung Center,

${ }^{4}$ School of Life Sciences, University of Nottingham, NG7 2UH, England, United Kingdom

${ }^{5}$ Department of Applied Chemistry and Biochemistry, University for Development Studies, Navrongo Campus, P.O. Box 24, Navrongo, Ghana, West Africa.

${ }^{6}$ Department of Biochemistry and Microbiology, University of Ouagadougou, Ouagadougou, 


\section{ABSTRACT}

2 Aim. Household insect pests, including cockroaches, have gained consideration as potential

3 vectors for multidrug resistant pathogens of public health concern. This study was designed to

4 investigate whether household cockroaches share beta-lactam resistance determinants with human

5 inhabitants.

6 Methods. From February through July 2016, 400 cockroaches were systematically collected from

$7 \quad 100$ households. Whole insect homogenates and faecal samples from inhabitants of all included

8 households were cultured for cephalosporin-resistant enterobacteria (CRe). The CRe were

9 examined for AmpC, ESBL, and carbapenemase genes; antibiotic susceptibility patterns; and

10 conjugative transfer of antibiotic resistance mechanisms. Clonal relationships between isolates

11 were determined by multi-locus sequence typing (MLST).

12 Results. Twenty CRe were recovered from whole cockroach homogenates of 15 households. Five

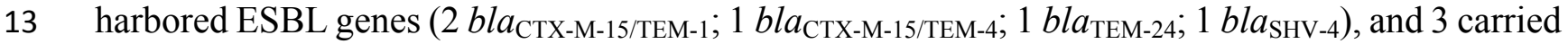

14 carbapenemase genes ( $2 b^{b l a_{\mathrm{NDM}-1}}$ genes and $1 b l a_{\mathrm{OXA}-48}$ gene) $\square$ all of which were transferrable by

15 conjugation to $E$. coli $\mathrm{J} 53$ recipients. There was high clonal diversity with low inter-species

16 similarity regardless of the beta-lactamase gene sequence. From 6 households, the pair of

17 cockroach and human CRe shared the same antibiogram, ST and/or conjugable bla $a_{\mathrm{ESBL}}$ gene

18 sequence (house 34, E. coli $\mathrm{ST} 9-b l a_{\mathrm{TEM}-4}$; house 37 , E. coli $\mathrm{ST} 44-b l a_{\mathrm{CTX}-15 / \mathrm{TEM}-4}$; house 41 , E. coli

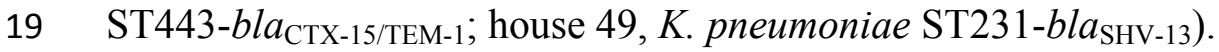

20 Conclusion. The findings highlight household cockroaches as reservoirs of CTX-M-15, OXA-48

21 and NDM-1 genes that share beta-lactam resistance determinants with humans. 


\section{Introduction}

2 The production of extended-spectrum beta-lactamases (ESBL), Class C cephalosporinases and

3 carbapenemases constitute the primary antibiotic resistance mechanism in Enterobacteriaceae

$4[1,2]$. Together, these beta-lactamases confer resistance to all available beta-lactam antibiotics, and

5 are associated with significantly high levels of co-resistance to other classes of broad spectrum

6 antimicrobials [1-6]. Increasingly, the CTX-M-15 type ESBLs are becoming predominant in

7 Ghana [7,8]. Occurrence of the recently described OXA-48 type carbapenemase and widespread

8 reports of bla $a_{\mathrm{NDM}-1}$ genes across Africa further compound the outlook of the antibiotic resistance

9 problem [9-13]. Indeed, emergence of such resistant bacteria is often related to misuse and abuse

10 of beta-lactam antibiotics $[14,15]$. However, the burden of such pathogens is also hugely aided by

11 poor sanitation [16-18]. Cockroaches, which widely colonize the environment, including human

12 dwellings, may well act as vectors of antibiotic-resistant bacteria.

13 Cockroaches are abundant in Ghanaian households and are known to harbor an array of pathogens

14 [19]. They often reside in household sewage pipe systems, which are a repository of diverse

15 infectious microorganisms. That cockroaches carry pathogenic bacteria is well documented in

16 literature [19-23]. Some of the pathogenic bacteria may be carriers of drug-resistance

17 determinants, particularly beta-lactamases. However, only few studies have investigated AmpC,

18 ESBL or carbapenemase resistance elements in bacteria from cockroaches[24]. Consequently, the

19 vector potential of cockroaches in the dissemination of such multidrug-resistance mechanisms is

20 largely under-reported. In this study, we report the presence of CTX-M-15-, OXA-48- and NDM-

21 1- producing bacteria in household cockroaches $\square$ with particular focus on the conjugability of

22 beta-lactam resistance determinants and clonal transmission to humans. 


\section{Methods}

\section{Study design and setting}

3 Between February and July 2016, a cross-sectional study was conducted to collect cockroaches

4 and human faecal samples from households in Ashaley Botwe, an urban municipality setting in

5 Accra, Ghana. The municipality has a population of approximately 78,215, with most households

6 occupied by an average of 5.6 persons[25]. The major source of water is pipe borne, and most of

7 the households have proper sewage disposal systems with flush toilets and standardized septic

8 tanks. Hundred households were selected by systematic random sampling using the Kish

9 method[26] which statistically allowed for equal chances of selecting any household in the

10 community. The selected households were approximately 150 metres from each other. From each

11 household, live indoor cockroaches were collected. Stool samples were also collected from

12 inhabitants of each household. The study received ethical approval from the Ethics and Protocol

13 Review Committee of the School of Biomedical and Allied Health Sciences, University of Ghana,

14 with approval identification number: SBAHS-MD./10512194/aa/5a/2016-2017. All human

15 participants provided written informed consents.

\section{Sample collection and processing}

17 All 100 households were provided with $100 \mathrm{ml}$ sterile containers with screw caps, sterile zipper

18 bags containing gloves and forceps to use for capturing cockroaches. A member of each household

19 was selected and educated appropriately to be responsible for capturing cockroaches. Only live

20 cockroaches found indoors were captured for this study. Four cockroaches (irrespective of species)

21 were requested per household and pooled as one sample. Each cockroach sample was soaked in

$2240 \mathrm{~mL}$ of Brain Heart Infusion broth (Sigma, UK), vortexed vigorously for 6 minutes, and ground 
1 with a sterile rod. The triturate was once again vortexed vigorously for 6 minutes to obtain a whole insect homogenate. A loop-full (approximately $10 \mu \mathrm{L}$ ) of suspension from each sample was inoculated onto SSI agar plate (SSI, Diagnostica, Denmark) with $30 \mu \mathrm{g}$ cefpodoxime disk (MAST, UK) and incubated overnight at $37^{\circ} \mathrm{C}$. For stool samples, 1 gram of each specimen was suspended in $10 \mathrm{ml}$ of sterile $0.9 \%$ physiological saline and vigorously vortexed. $1 \mathrm{ml}$ of the suspension was cultured on SSI agar plates with $30 \mu \mathrm{g}$ cefpodoxime disk. From each culture plate, distinct morphological phenotypes of enterobacteria growing around the cefpodoxime disks within an inhibition zone of $21 \mathrm{~mm}$ were defined as screen positive for third generation cephalosporin resistance $(\mathrm{CRe})$. Each distinct morphological phenotype was identified to the species level using the biochemical test kits Minibact-E® (SSI, Diagnostica, Denmark) according to the manufacturer's guidelines. Subsequently, four colonies of each speciated phenotype were subjected to the Kirby-Bauer method of susceptibility testing per guidelines of the Clinical and Laboratory Standard Institute (CLSI) using cefotaxime (30 $\mu \mathrm{g})$ and ceftazidime (30 $\mu \mathrm{g})$ antibiotics [27]. Isolates resistant to cefotaxime or ceftazidime were confirmed as CRe.

\section{Susceptibility test and assays for ESBL, AmpC and carbapenemase}

All CRe isolates were tested for susceptibility to the following antibiotics (MAST, UK) according to CLSI guidelines[27]: ampicillin $(10 \mu \mathrm{g})$, augmentin $(10 \mu \mathrm{g} / 260 \mu \mathrm{g})$; meropenem $(10 \mu \mathrm{g})$, tetracycline $(30 \mu \mathrm{g})$, chloramphenicol $(30 \mu \mathrm{g})$, cotrimoxazole $(100 \mu \mathrm{g} / 240 \mu \mathrm{g})$, gentamicin $(10$ $\mu \mathrm{g})$, ciprofloxacin $(5 \mu \mathrm{g})$, nitrofurantoin $(100 \mu \mathrm{g})$; piperacillin/tazobactam $(10 / 30 \mu \mathrm{g})$, cefoxitin $(30 \mu \mathrm{g})$, ceftaroline $(30 \mu \mathrm{g})$, and tigecycline $(30 \mu \mathrm{g})$. Klebsiella pneumoniae ATCC 700603 and Escherichia coli ATCC 25922 were used as quality control strains. Ceftaroline breakpoint was interpreted with European Committee for Antibiotic Susceptibility Testing (EUCAST) guidelines[28].Phenotypic detection of ESBL production was by the combination disk method 
1 with cefotaxime $(30 \mu \mathrm{g})$ or ceftazidime $(30 \mu \mathrm{g})$, alone or in combination with clavulanic acid (10

$\mu \mathrm{g})$ [29]. AmpC expression was suspected in isolates with reduced susceptibility (inhibition zone $<20 \mathrm{~mm})$ to cefoxitin $(30 \mu \mathrm{g})$. AmpC confirmation was by the use of cefotaxime $(30 \mu \mathrm{g}) \mathrm{or}$ ceftazidime $(30 \mu \mathrm{g})$ tablets, with or without boronic acid $(250 \mathrm{ug})$ as per the manufacturer's guidelines (Rosco Diagnostica, Taastrup, Denmark). An increase of $\geq 5 \mathrm{~mm}$ in zone diameter, due to boronic acid, was considered AmpC positive. Isolates with inhibition zone of $<21 \mathrm{~mm}$ for 10 $\mu \mathrm{g}$ meropenem were considered carbapenem resistant [29]. Carbapenem resistant isolates were confirmed for class A and B carbapenemase using boronic acid $(600 \mu \mathrm{g})$ and EDTA $(750 \mu \mathrm{g})$ effect, respectively, on meropenem (10 $\mu \mathrm{g})$. Strains with boronic acid or EDTA effect of $\geq 5 \mathrm{~mm}$ increase in zone diameter were considered positive for class A or B carbapenemase phenotype, respectively. Carbapenem resistant strains that were not susceptible to temocillin $(30 \mu \mathrm{g})$ were considered positive for OXA-48 like carbapenemase. Carbapenem resistant strains were also subjected to the Modified Hodges Test [29].

\section{Genotypic characterization}

Gene amplification and sequencing was done for ESBL-, AmpC-, and carbapenemase-producing isolates as well as their transconjugants. For each isolate, $10 \mu \mathrm{L}$ of pure culture on Mueller Hinton agar was suspended in $300 \mu \mathrm{L}$ Milli-Q ${ }^{\circledR}$ water, heated for 10 minutes at $98^{\circ} \mathrm{C}$, and subsequently centrifuged for 5 minutes at $4{ }^{\circ} \mathrm{C}$ and $20.000 \mathrm{~g}$. The supernatant DNA lysate was transferred into sterile $1.5 \mathrm{ml}$ Eppendorf ${ }^{\circ}$ tubes for storage at $-5^{\circ} \mathrm{C}$. See supplementary Table for amplification primers and conditions. For ESBLs, PCR was performed for $b l a_{\mathrm{TEM}}, b l a_{\mathrm{SHV}}, b l a_{\mathrm{CTX}-\mathrm{M}-1}, b l a_{\mathrm{CTX}-\mathrm{M}-}$ ${ }_{2}, b l a_{\mathrm{CTX}-\mathrm{M}-9}, b l a_{\mathrm{OXA}-2}, b l a_{\mathrm{OXA}-10}$. Isolates with AmpC phenotypes were examined for 6 families of plasmid-mediated AmpC genes including MOX, CMY, DHA, ACC, EBC and FOX using the multiplex assay[30]. For carbapenemases, PCRs were designed for specific genes belonging to 
1 class A, B, and D carbapenemase phenotypes. A multiplex PCR assay was performed to

2 differentiate 5 genes (GES, KPC, SME, INI-NMC-A) for class A carbapenemase, and 6 genes

3 (IMP, VIM, GIM, SPM, SIM, and NDM-1) for class B phenotypes[31]. Isolates with Class D

4 carbapenemase phenotypes were examined for OXA-48 like genes. Additional internal primers

5 (supplementary data 1) were used for sequencing CTX-M-1, CTX-M-9, SHV and TEM genes.

6 Nucleotide and deduced protein sequences were compared with sequences in the NCBI database

7 (http://www.ncbi.nlm.nih.gov/BLAST). TEM and SHV beta-lactamase sequences were compared

8 to wild-type E. coli TEM-1 and SHV-1 at http://www.lahey.org/studies. For Multilocus Sequence

9 Typing (MLST), we used the the previously described E. coli protocol by Wirth et al. [32] and the

10 PubMLST scheme for K. pneumoniae (http://pubmlst.org/kpneumoniae/). Seven housekeeping

11 genes were amplified and sequenced for each E.coli (adk, fumC, gyr, icd, mdh, purA and recA)

12 and K. pneumoniae (gapA, infB, mdh, pgi, phoE, rpoB, tonB). Resulting sequences of the seven

13 house-keeping genes were analysed using the CodonCode Aligner software version 8.1

14 (Germany). The MLST sequence types (ST) and clonal complexes (CC) were assigned in

15 accordance to the online platform PubMLST database. Phylogenetic minimum spanning tree was

16 constructed using the online programme PHYLOViZ [33].

\section{Conjugation}

All CRe isolates were included in the conjugation assay. Conjugations were done using sodium azide-resistant E. coli J53 as recipient [34]. None of the CRe showed resistance to sodium azide. The donors were cultured in Luria-Bertani (LB) (MAST, UK) broth with cefotaxime $(8 \mu \mathrm{g} / \mathrm{ml})$

21 overnight. The recipient was also cultured overnight in LB broth but with no antibiotic.

22 Subsequently, $1 \mathrm{~mL}$ aliquots of each donor and the recipient were separately transferred into fresh

$2310 \mathrm{ml} \mathrm{LB}$ broth and incubated for 2 hours at $37^{\circ} \mathrm{C}$. For each donor, $100 \mu \mathrm{L}$ of culture was mixed 
1 with an equal volume of the recipient and the mixture was incubated for 6 hours at $37^{\circ} \mathrm{C}$. Selection

2 for transconjugants was carried out on MacConkey agar supplemented with sodium azide (150

$3 \mathrm{mg} / \mathrm{L})$ and cefotaxime $(8 \mathrm{mg} / \mathrm{L})$ or cefoxitin $(32 \mathrm{mg} / \mathrm{L})$ or meropenem $(2 \mathrm{mg} / \mathrm{L})$. Transconjugants

4 were confirmed for ESBL, AmpC or carbapenemase genotype as previously described.

\section{Data analysis}

6 Data were entered into a Microsoft Excel sheet for editing and analysis. Results are presented using

7 descriptive analysis with proportions and percentages. Multidrug-resistant (MDR) isolates were

8 those resistant to at $\geq 1$ agent in $\geq 3$ ntimicrobial categories (aminoglycosides, flouoroquinolones,

9 penicillins, penicillins/ $\beta$-lactamase inhibitors, antipseudomonal penicillins/ $\beta$-lactamase inhibitors,

10 cephamycins, anti-MRSA cephalosporins, $1^{\text {st }}$ and $2^{\text {nd }}$ generation cephalosporins, $3^{\text {rd }}$ and $4^{\text {th }}$

11 generation cephalosporins, monobactams, Carbapenems, polymixins, phosphonic acids, folate-

12 pathway inhibitors, Glycylcyclines, phenicols). Extensively drug-resistant (XDR) isolates were

13 non-susceptible to $\geq 1$ agent in all but $\leq 2$ antimicrobial categories. Conjugation frequency per

14 recipient was expressed by dividing the number of transconjugants by the initial number of 15 recipients. 


\section{$1 \quad$ RESULTS}

2 The study procedures and outcomes are summarized in Fig 1. All 100 insect homogenates yielded

3 polymicrobial cultures after inoculation onto SSI agar with $10 \mu \mathrm{g}$ cefpodoxime disks. Fifteen of

4 the homogenate cultures were screen positive for CRe. Of these, 10 grew only one dominating

5 colony type and 5 had two morphologicaly diferent dominant isolates with distinct antibiograms $\square$

6 corresponding to 20 screen positive Enterobacteriaceae isolates (Table 1). The 20 isolates were

7 each resistant to cefotaxime or ceftazidime antibiotic by the Kirby-Bauer method of sensitivity

8 testing, and were thus confirmed as cockroach CRe. Overall, 61 fecal samples were collected from

9 all inhabitants of 15 households that had cockroach samples positive for CRe. The average number

10 of inhabitants per household was $4 \pm 1.3$. Fifteen $(24.5 \%)$ of the 61 faecal samples were screen

11 positive for CRe on SSI agar plate. These included 10 faecal cultures that yielded only one

12 dominant colony type and 5 that cultured two morphologicaly different dominating isolates with

13 completely different antibiograms $\square$ corresponding to 20 screen positive CRe. All 20 screen

14 positive CRe were resistant to cefotaxime or ceftazidime antibiotic disk, and were assigned human

15 CRe.

17 Fig 1. Summary of study protocols and outcomes. This is flow chart outline of study procedures 18 and results.

\section{Characterization of CRe}

21 Of the 20 cockroach CRe, 12 isolates (from 10 samples) expressed ESBL $(n=5), A m p C(n=4)$ or

22 were resistant to meropenem $(\mathrm{n}=3)$ (Table 1). The AmpC-producers were Enterobacter freundii $23(\mathrm{n}=2)$ and Enterobacter agglomerans $(\mathrm{n}=2)$. Isolates with ESBL phenotype included 4 E. coli and 
$11 \mathrm{~K}$. pneumoniae. Two of the 3 meropenem resistant isolates (E. freundii and C. cloacae) were

2 found to be metallo-beta-lactamse (MBL)-producers. The third (E. coli) was non-susceptible to

3 temocillin (30 ug); and was deemed presumptively positive for OXA-48 like carbapenemase

4 (Table 1). None of the CRe isolates was positive for any combination of the three phenotypes. Of

5 the 5 ESBL-producers, PCR and nucleotide sequencing identified bla $a_{\mathrm{CTX}-\mathrm{M}-15 / \mathrm{TEM}-1}$ in 2 E. coli

6 isolates (Table 1). The remaining 3 harboured either $b l a_{\mathrm{CTX}-\mathrm{M}-15 / \mathrm{TEM}-4}, b l a_{\mathrm{TEM}-24}$ or $b l a_{\mathrm{SHV}-3} \mathrm{ESBL}$

7 genes. None of the AmpC-producers had an identifiable plasmid-mediated AmpC gene. The 2

8 MBL-positive isolates each carried $b l a_{\mathrm{NDM}-1}$ gene. The meropenem resistant $E$. coli with non-

9 susceptibility to temocillin carried $b l a_{\mathrm{OXA}-48}$ gene. Antibiogram of the 20 cockroach CRe revealed

10 differences in resistance patterns between ESBL-, AmpC- or carbapenemase-positive isolates and

11 those CRe negative for the 3 phenotypes (Table 1). The CRe without any of the phenotypes were

12 MDR phenotypes in 3 of 8 isolates. They were susceptible to most of the non-beta-lactam

13 antibiotics, with all 8 isolates susceptible to gentamicin $(n=7 / 7)$, tigecycline $(n=7 / 7)$,

14 chloramphenicol $(\mathrm{n}=8 / 8)$, and nitrofurantoin $(\mathrm{n}=7 / 7)$. In contrast, MDR phenotype was reported in

15 all isolates with ESBL or AmpC phenotype. Two of the 3 carbapenemase-positive CRe were also

16 XDR. Table 2 shows the molecular characterization and antibiogram of all 20 human CRe. None

17 was positive for AmpC or carbapenemase phenotype. Five CRe expressed ESBLs (4 E. coli and 1

$18 K$. pneumoniae). When the ESBL-producing faecal isolates were subjected to PCR and

19 sequencing, the $K$. pneumoniae carried bla $a_{\mathrm{SHV}-3}$. The 4 E. coli separately harboured bla $a_{\mathrm{TEM}-24}$,

$20 b l a_{\mathrm{TEM}-14}, b l a_{\mathrm{CTX}-\mathrm{M}-15 / \mathrm{TEM}-4}$, and $b l a_{\mathrm{CTX}-\mathrm{M}-15 / \mathrm{TEM}-1 .}$ The antibiotic susceptibility profile of all 20

21 human CRe mirrored that observed for cockroach isolates $\square$ with clear differences in resistance

22 pattern between ESBL- and non-ESBL producers (Table 2). 
Table 1. Characteristics of $20 \mathrm{CRe}$ recovered from 100 whole insect homogenates.

\begin{tabular}{|c|c|c|c|c|c|c|c|c|c|c|c|c|c|c|c|c|c|c|c|c|c|}
\hline \multicolumn{2}{|r|}{ Homogenate samples } & \multirow{2}{*}{$\begin{array}{l}\text { Beta-lactamase } \\
\text { phenotype }\end{array}$} & \multirow{2}{*}{$\begin{array}{l}\text { Cephalosporin resistant } \\
\text { gene }\end{array}$} & \multirow{2}{*}{$\mathrm{C}+$} & \multicolumn{16}{|c|}{ Antibiotic resistance* } & \multirow[b]{2}{*}{ MDR } \\
\hline House & CRe isolate & & & & $\overline{\mathrm{Gn}}$ & Tgc & Cip & Cot & Mer & Fox & Cfx & Ctx & Amp & Aug & Chl & Tet & Nit & Azt & Ptz & $\mathrm{Cpt}$ & \\
\hline 2 & Citrobacter freundi & Carbapenemase & $b l a_{\mathrm{NDM}-1}$ & & & & & & & $\mathrm{R}$ & & & $\mathrm{R}$ & $\mathrm{R}$ & & & & & & & XDR \\
\hline 13 & Enterobacter cloacae & Carbapenemase & $b l a_{\mathrm{NDM}-1}$ & & & & & & & $\mathrm{R}$ & & & $\mathrm{R}$ & $\mathrm{R}$ & & & & & & & \\
\hline 34 & Escherichia coli & Carbapenemase & $b l a_{\text {OXA-48 }}$ & & & & & & & & & & & & & & & & & & $\mathrm{XDR}$ \\
\hline 34 & Escherichia coli & ESBL & $b l a_{\text {TEM-24 }}$ & & & & & & & & & & & & & & & & & & \\
\hline 37 & Escherichia coli & ESBL & $b l a_{\mathrm{CTX}-\mathrm{M}-15}$ and $b l a_{\mathrm{TEM}-4}$ & & & & & & & & & & & & & & & & & & \\
\hline 39 & Escherichia coli & ESBL & $b l a_{\mathrm{CTX}-\mathrm{M}-15}$ and $b l a_{\mathrm{TEM}-1}$ & & & & & & & & & & & & & & & & & & \\
\hline 41 & Escherichia coli & ESBL & $b l a_{\mathrm{CTX}-\mathrm{M}-15}$ and $b l a_{\mathrm{TEM}-1}$ & & & & & & & & & & & & & & & & & & \\
\hline 49 & Klebsiella pneumoniae & ESBL & $b l a_{\mathrm{SHV}-3}$ & & & & & & & & & & $\mathrm{R}$ & & & & & & & & \\
\hline 2 & Citrobacter freundi & AmpC & no $\mathrm{pAmpC}$ & & & & & & & & & & $\mathrm{R}$ & $\mathrm{R}$ & & & & & & & \\
\hline 59 & Citrobacter freundi & $\mathrm{AmpC}$ & no $\mathrm{pAmpC}$ & & & & & & & & & & $\mathrm{R}$ & $\mathrm{R}$ & & & & & & & \\
\hline 65 & Enterobacter agglomerans & AmpC & no $\mathrm{pAmpC}$ & & & & & & & & & & $\mathrm{R}$ & $\mathrm{R}$ & & & & & & & \\
\hline 65 & Enterobacter agglomerans & AmpC & no $\mathrm{pAmpC}$ & & & & & & & & & & $\mathrm{R}$ & $\mathrm{R}$ & & & & & & & \\
\hline 37 & Escherichia coli & $\mathrm{CRe}$ & nd & & & & & & & & & & & & & & & & & & \\
\hline 69 & Enterobacter kobei & $\mathrm{CRe}$ & nd & & & & & & & & & & $\mathrm{R}$ & $\mathrm{R}$ & & & & & & & \\
\hline 71 & Klebsiella oxytoca & $\mathrm{CRe}$ & nd & & & & & & & & & & $\mathrm{R}$ & & & & & & & & \\
\hline 39 & Escherichia coli & $\mathrm{CRe}$ & nd & & & & & & & & & & & & & & & & & & \\
\hline 81 & Escherichia coli & $\mathrm{CRe}$ & nd & & & & & & & & & & & & & & & & & & \\
\hline 84 & Proteus mirabilis & $\mathrm{CRe}$ & nd & & & $\mathrm{R}$ & $\mathrm{R}$ & & & & & & & & & $\mathrm{R}$ & $\mathrm{R}$ & & & & \\
\hline 86 & Citrobacter amolaniticus & $\mathrm{CRe}$ & nd & & & & & & & & & & $\mathrm{R}$ & $\mathrm{R}$ & & & & & & & \\
\hline 91 & Salmonella cholaerae suis & $\mathrm{CRe}$ & nd & & $\mathrm{R}$ & & & & & $\mathrm{Nd}$ & $\mathrm{Nd}$ & & & & & & & & & & \\
\hline
\end{tabular}

$2 *$ As per column headings, dark cells indicate "yes"; white cells indicate "no" C+, successfully transferred the beta-lactamase encoding genotype to J53 E.coli recipient via

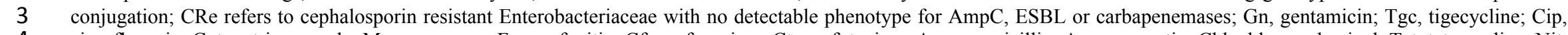

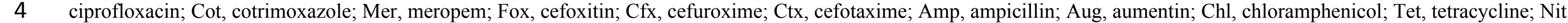

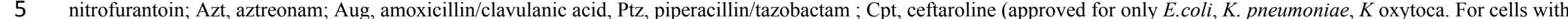

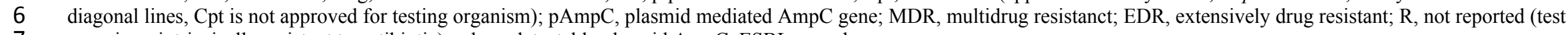
7 organisms intrinsically resistant to antibiotic); nd, no detectable plasmid AmpC, ESBL or carbapenemase gene. 


\begin{tabular}{|c|c|c|c|c|c|c|c|c|c|c|c|c|c|c|c|c|c|c|}
\hline \multirow[b]{2}{*}{ House CRe isolate } & \multirow{3}{*}{$\begin{array}{c}\beta \text {-lactamase } \\
\text { phenotype }\end{array}$} & \multirow{2}{*}{$\begin{array}{l}\text { Number } \\
\text { of persons }\end{array}$} & \multicolumn{13}{|c|}{ Antibiotic resistance* } & \multirow[b]{2}{*}{ MDR } & \multirow[b]{2}{*}{$\begin{array}{c}\beta \text {-lactamase encoding } \\
\text { genes }\end{array}$} & \multirow[b]{2}{*}{$\mathrm{C}+$} \\
\hline & & & Gn Tgc & Cip & Cot & Mer Fox & Cfx & Ctx & Amp & Aug Chl & Tet & Nit & Azt & Ptz & Cpt & & & \\
\hline Escherichia coli & & 1 of 3 & & & & & & & & & & & & & & & none found & \\
\hline 13 K. oxytoca & CRe & 2 of 4 & & & & & & & $\mathrm{R}$ & & & & & & & & none found & \\
\hline 13 Escherichia coli & $\mathrm{CRe}$ & & & & & & & & & & & & & & & & none found & \\
\hline $34 \quad$ Escherichia coli & ESBL & 1 of 5 & & & & & & & & & & & & & & & $b l a_{\mathrm{TEM}-24}$ & \\
\hline $37 \quad$ Escherichia coli & ESBL & 1 of 3 & & & & & & & & & & & & & & & $b l a_{\mathrm{CTX}-\mathrm{M}-15}$ and $b l a_{\mathrm{TEM}-4}$ & \\
\hline 39 Escherichia coli & $\mathrm{CRe}$ & 1 of 5 & & & & & & & & & & & & & & & none found & \\
\hline 41 Escherichia coli & ESBL & 2 of 5 & & & & & & & & & & & & & & & bla $a_{\text {CTX_-M-14 }}$ & \\
\hline 41 Escherichia coli & ESBL & & & & & & & & & & & & & & & & $b l a_{\mathrm{CTX}-\mathrm{M}-15}$ and $b l a_{\mathrm{TEM}-1}$ & \\
\hline 49 Klebisella pneumoniae & ESBL & 1 of 5 & & & & & & & $\mathrm{R}$ & & & & & & & & bla $_{\mathrm{SHV}-3}$ & \\
\hline 59 Escherichia coli & $\mathrm{CRe}$ & 1 of 3 & & & & & & & & & & & & & & & none found & \\
\hline 65 Escherichia coli & $\mathrm{CRe}$ & 1 of 2 & & & & & & & & & & & & & & & none found & \\
\hline 69 Escherichia coli & CRe & 2 of 3 & & & & & & & & & & & & & & & none found & \\
\hline 69 Klebisella pneumoniae & $\mathrm{CRe}$ & & & & & & & & & & & & & & & & none found & \\
\hline 71 Escherichia coli & CRe & 2 of 2 & & & & & & & & & & & & & & & none found & \\
\hline 71 Klebisella pneumoniae & $\mathrm{CRe}$ & & & & & & & & $\mathrm{R}$ & & & & & & & & none found & \\
\hline 81 Escherichia coli & CRe & 2 of 5 & & & & & & & & & & & & & & & none found & \\
\hline 81 Citrobacter koseri & $\mathrm{CRe}$ & & & & & $\mathrm{R}$ & & & & $\mathrm{R}$ & & & & & & & none found & \\
\hline 84 Escherichia coli & $\mathrm{CRe}$ & 1 of 3 & & & & & & & & & & & & & & & none found & \\
\hline 86 Escherichia coli & $\mathrm{CRe}$ & 1 of 6 & & & & & & & & & & & & & & & none found & \\
\hline 91 Escherichia coli & $\mathrm{CRe}$ & 1 of 6 & & & & & & & & & & & & & & & none found & \\
\hline
\end{tabular}

* As per column headings, dark cells indicate "yes"; white cells indicate "no" C+, successfully transferred the beta-lactamase encoding genotype to J53 E.coli recipient via conjugation;

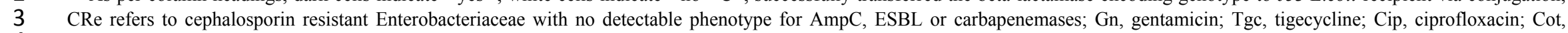

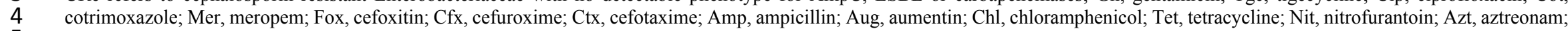

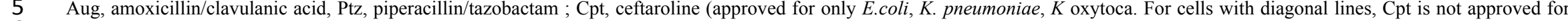

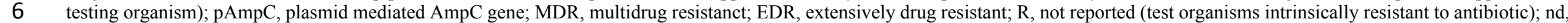
no detectable plasmid AmpC, ESBL or carbapenemase gene 


\section{Conjugation Assays}

2 The 20 CRe each from cockroach and human inhabitants were subjected to conjugation

3 experiments (Table 3). All CRe negative for ESBLs, AmpCs or carbapenemases could not transfer

4 their cephalosporin resistance to E. coli J53 recipients. Similarly, none of the AmpC-producing

5 isolates transferred the phenotype. Successful conjugative experiments were demonstrated only in

6 ESBL- or carbapenemase-producing isolates (Table 3). For these isolates, PCR amplification and

7 sequencing of the ESBL or carbapenemase genes in the E. coli J53 transconjugants showed the

8 same bla gene types previously identified in the donor isolates. The ESBL genes in human isolates

9 transferred at significantly lower conjugation frequencies (range: $1.1 \times 10^{-5}-1.9 \times 10^{-4}$ ) compared to

10 those from cockroach isolates (range: $2.3 \times 10^{-3}-4.8 \times 10^{-2}$ ). For cockroach isolates, carbapenemase

11 genes appeared to conjugate with lower efficiency (range: $1.1 \times 10^{-3}-1.9 \times 10^{-3}$ ) compared to ESBL

12 genes (range: $2.3 \times 10^{-3}-4.8 \times 10^{-2}$ ). Resistance to non- $\beta$-lactam antimicrobials was also co-

13 transferred in some cases, in addition to transfer of ESBL or carbapenemase phenotype. The most

14 frequently co-transferred antibiotic resistance phenotype in transconjugants were cotrimoxazole,

15 followed by tetracycline and then ciprofloxacin. Tigecycline and nitrofurantoin resistance did not

16 transfer to recipients despite repeated attempts. 
Table 3. Conjugation characteristics of ESBL- and carbapenemase-producing CRe isolated from cockroaches and humans

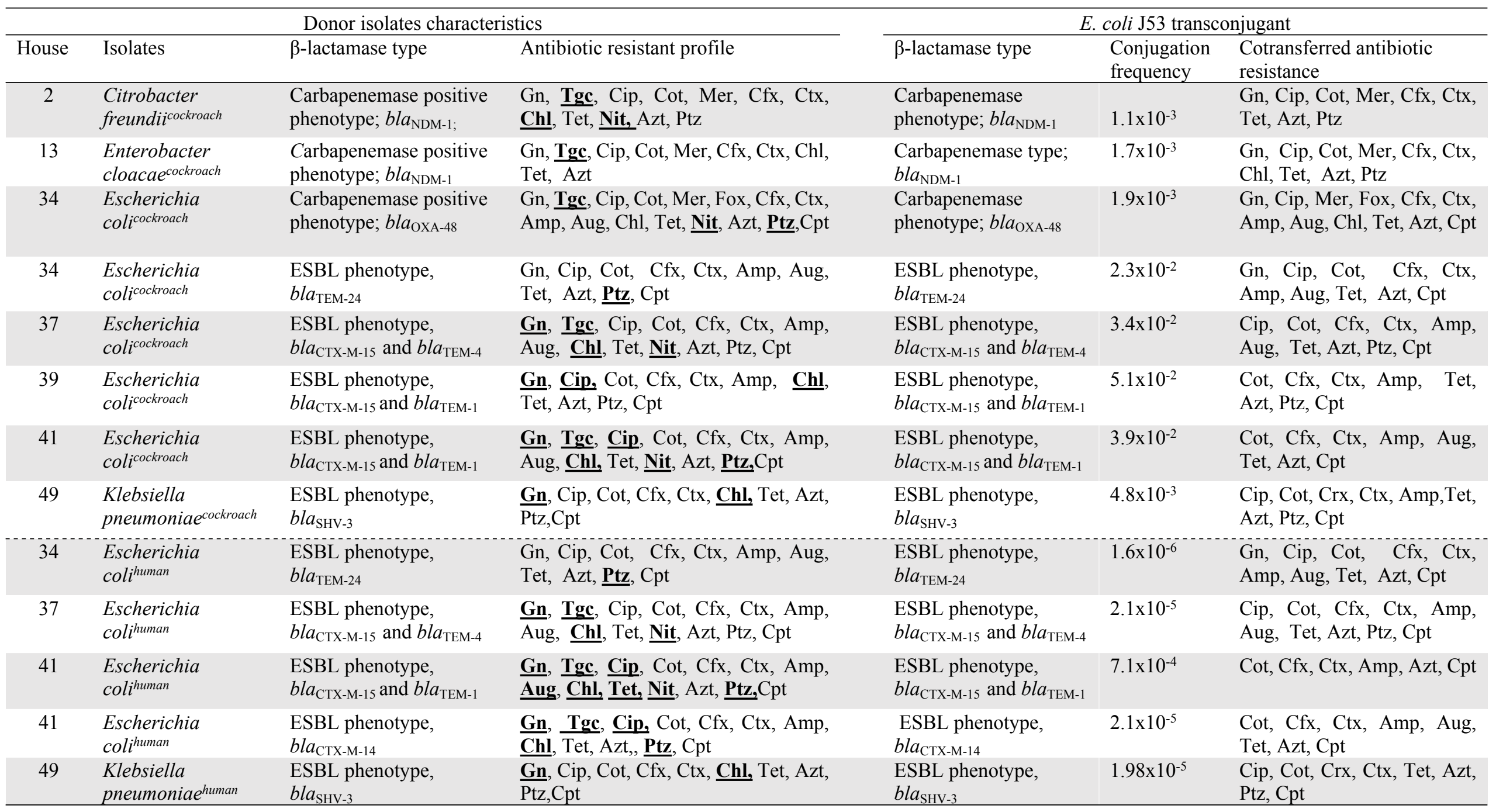

2 *Highlighted antibiotics were not cotransferred to transconjugants; Gn, gentamicin; Tgc, tigecycline; Cip, ciprofloxacin; Cot, cotrimoxazole; Mer, meropem; Fox, cefoxitin; Cfx,

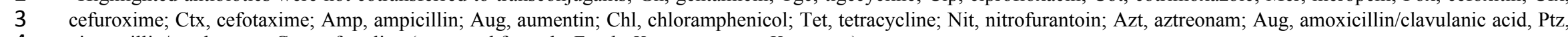

4 piperacillin/tazobactam, Cpt, ceftaroline (approved for only E.coli, K. pneumoniae, K oxytoca) 


\section{Phylogenetic analysis}

2 Overall, there were 20 Cockroach CRe and 20 human CRe. Of these, we compared by MLST the

3 top 2 predominant isolates E. coli $(\mathrm{n}=23)$ and $K$. pneumoniae $(\mathrm{n}=4)$. There was high clonal

4 diversity with low inter-species similarity regardless of the beta-lactamase gene sequence (Fig 2).

5 Four E. coli STs and clonal complexes were found in cockroach CRe (ST48/CC10, ST101/CC101,

6 ST367/CC23, ST405/CC405). Among human CRe, we found 5 E. coli STs with associated clonal

7 complexes (ST88/CC23, ST162/CC469, ST189/CC165, ST215/CC10, ST341/CC205) and 5

8 singleton STs (ST117, ST542, ST871, ST1250, ST1287). The K. pneumoniae STs identified in

9 only humans were ST171 and ST244 singletons. The following STs with clonal complex were

10 detected in CRe from both human and cockroach samlples (E. coli: ST9/CC20, ST44/CC10,

11 ST443/CC205, ST453/CC86; K. pneumoniae: ST231/CC86). The E. coli ST215 was identified in

12 human CRe from 2 households. In one clonal complex (CC10), the genotype was detected in 3

13 households, all from human CRe.

Fig 2. Minimum spanning tree based on MLST allelic profiles of CRe from human and

cockroach samples. Minimum spanning tree based on MLST allelic profiles of cephalosporin

17 resistant E. coli and K. pneumoniae in human and cockroach samples from household. Each circle an ST identified in cockroach CRe. The circle in blue (or the upper half) represents an ST identified in human CRe. The numbers on the connecting lines illustrate the number of differing alleles. The

22 detectable pAmpC, ESBL or carbapenemase gene. 


\section{Comparison of cockroach and human CRe}

2 In this study, all cockroach CRe isolates belonged to households with human inhabitants colonized

3 by CRe. Thus there were 15 households with both cockroach and human CRe. Six households had

4 human and cockroach CRe of the same bacteria identity (E. coli or K. pneumoniae) (Table 5).

5 From 4 households, the pair of human and cockroach isolates shared the same ST and $b l a_{\mathrm{ESBL}}$ gene

6 sequence (house 34, E. coli ST9-bla TEM-4; $_{\text {; house 37, E. coli ST44-bla }}$ CTX-15/TEM-4; house 41, E. coli

7 ST443-bla $a_{\mathrm{CTX}-15 / \mathrm{TEM}-1}$; house 49, K. pneumoniae ST231-bla $\left.a_{\mathrm{SHV}-13}\right)$. The pair also had the same

8 antibiogram; and successfully transferred their ESBL phenotype and genotype by conjugation to

9 E. coli $\mathrm{J} 53$ recipients. In house 81, the CRe (from human and cockroach samples) belonged to the

10 same E. coli ST453 but exhibited different antibiogram with no identifiable ESBL, AmpC or

11 carbapenemase gene. The pair did not transfer their cephalosporin resistance phenotype by

12 conjugation to E. coli J53 recipients. One human inhabitant (house 41) was colonized by E. coli

13 ST341-bla $a_{\text {CTX-M-14 }}$ which was different from the corresponding cockroach isolate (E. coli ST443

14 with bla $a_{\mathrm{CTX}-15 / \mathrm{TEM}-1}$ ESBL gene). Both isolates however belonged to the same clonal complex 15 CC205. 
1 Table 4. MLST analysis of CRe from cockroach and human inhabitants

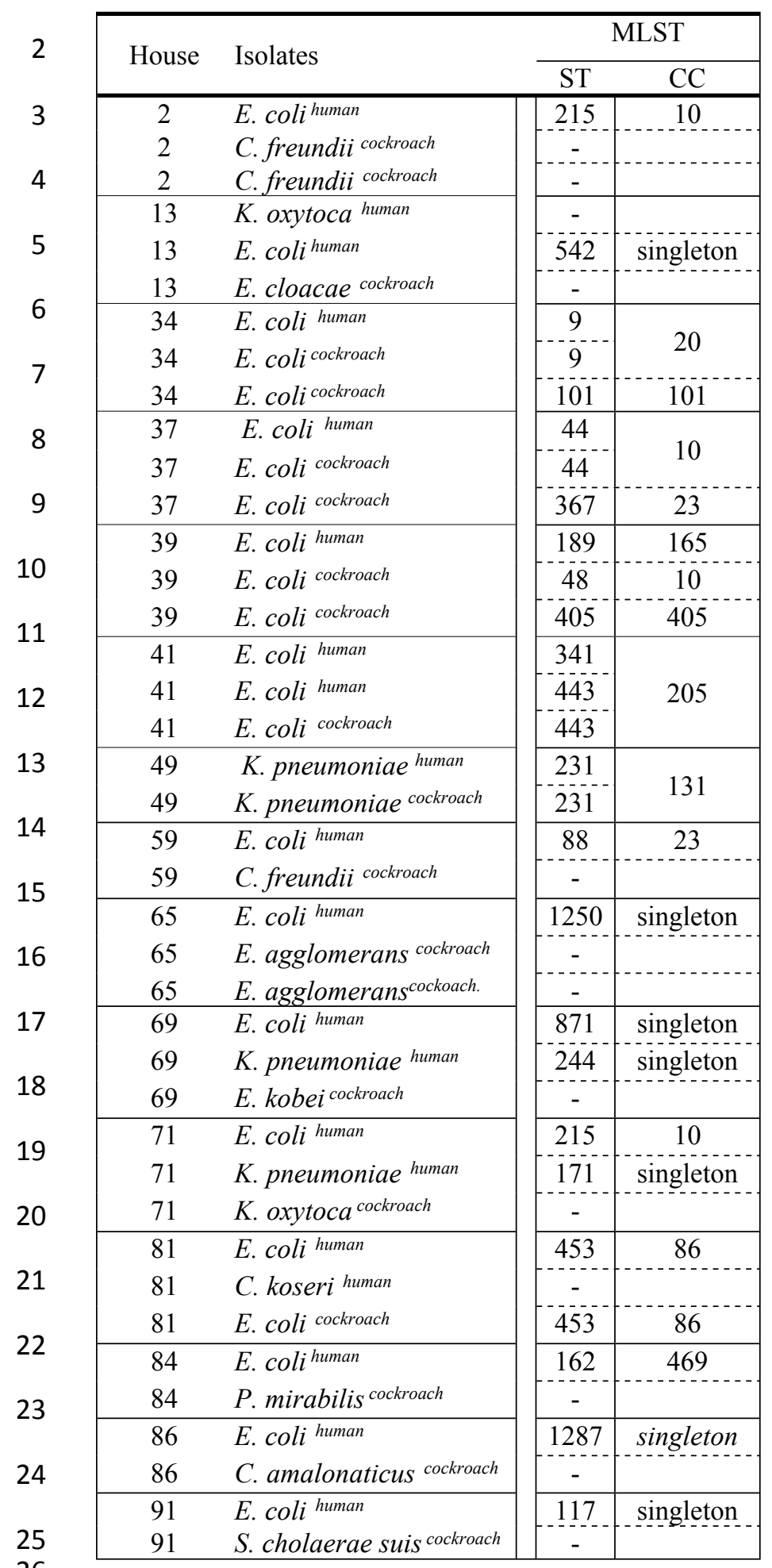

* $\mathrm{C}+$, conjugation tests; dark cells within the $\mathrm{C}+$ column show that the isolate successfully transferred their $\beta$-lactamase phenotype and genotype to J53 E.coli recipient via conjugation; white cells within the C+ column indicate unsuccessful conjugation of $\beta$-lactamase phenotype and genotype to J53 E.coli recipient via conjugation; MLST, multilocus sequence typing; ST, Sequence Type; CC, clonal complex 


\section{Discussion}

2 The direct transfer of AmpC-, ESBL-, or carbapenemase-producing bacteria to humans via insects

3 seems possible, but evidence is sparse [24,35]. Loucif et al. showed that 9 of 12 bacterial isolates

4 from cockroaches in an Algerian hospital harboured CTX-M-15 genes. Of these, one expressed an

5 OXA-48 type carbapenemase and belonged to the sequence type 528 [24]. Elsewhere, Fotedar and

6 colleagues indicated in an experimental study that insects fed with Pseudomonas aeruginosa could

7 excrete the bacteria even up to 114 days post-infection[35]. In our study, we report that

8 cockroaches carry MDR CTX-M-15, XDR OXA-48, and XDR NDM-1 producing enterobacteria;

9 and share the same STs and beta-lactam resistance determinants with humans in the household.

10 There is paucity of data on community-based molecular studies examining cockroach colonization

11 with carbapenemase producing Enterobacteriaceae, limiting the scope for comparing our results

12 with existing literature. To our knowledge this is the first published description of $b l a_{\mathrm{NDM}-1}$ and

$13 b l a_{\mathrm{OXA}-48}$ genes in enterobacteria recovered from household cockroaches.

14 Cockroaches often reside in household sewage systems. As they scurry, they contaminate surfaces

15 including utensils leading to the horizontal transmission of bacteria from person to person. Our

16 findings highlight the importance of cockroaches as potential reservoir of epidemiologically

17 significant multidrug resistant pathogens of public health concern. Some observations merit

18 attention. First, merely $4 \%$ of households had cockroach and human isolates from one house that

19 shared the same ST or clonal complex, antibiogram, bla $a_{\mathrm{ESBL}}$ gene sequence, and successfully

20 transferred their ESBL phenotype and genotype by conjugation to E. coli J53 recipients. The

21 results point to zoonotic transmission by clonal spread and highlight domestic cockroaches as

22 constituting a 'revolving door' through which ESBL-producing enterobacteria disseminate to

23 human contacts. The successful inter-genus conjugation events reported in this study suggest that, 
1 at least for the non- $E$. coli isolates used as donors, the plasmids involved are likely to be

2 conjugative plasmids with broad host range. This hints at the potential for these resistance

3 determinants to spread freely across bacterial species in the environment. Our results are

4 strengthened by other findings that have reported direct transfer of ESBL-producing bacteria to

5 humans via close contact with animal sources. Huijbers et al. revealed an increased risk for people

6 with close broiler contact as well as strong indications of the transmission from animals[36]. In a

7 comparative analysis of ESBL-Positive E. coli from animals and humans from the UK, the

8 Netherlands and Germany, Wu et al. showed that about $1.2 \%$ of the animal isolates shared the

9 same MLST CC with the human ones indicating that zoonotic transmission [37]. A direct transfer

10 from poultry to people with close contact has also been reported [38]. Second, the finding of

11 enterobacteria with $b l a_{\mathrm{NDM}-1}$ and $b l a_{\mathrm{OXA}-48}$ in household cockroaches is alarming given that the

12 strains could very quickly disseminate, and originate uncontrollable dissemination of pandemic

13 clones for which effective antibiotics may not be available in Ghana. The ease of transmission of

$14 b l a_{\mathrm{NDM}-1}$ genes have already been discussed by Karen Bush[2,39-41]. Interestingly, although the

17 the experience that carbapenem resistance is low $[6,42,43]$. Last, the antibiogram of isolates

18 described in this study do not differ from that generally reported for clinical strains. In this study, routinely used non-beta-lactam antibiotics including ciprofloxacin and gentamicin. It is the experience in Ghana that resistance to these antibiotics among clinical Enterobacteriaceae is

22 high[42,44,45]. It is widely presumed that such high levels of resistance are associated with 23 plasmid-mediated beta-lactamases. Indeed, our results show a clear separation, in which, the 
1 prevalence of resistance was higher among strains expressing ESBL, AmpC or carbapenemase

2 than those negative for the enzymes. The CRe isolates without ESBL, AmpC or carbapenemase

3 were susceptible to several antibiotics tested. None of these CRe also successfully transferred their

4 cephalosporin resistance phenotype to $E$. coli $\mathrm{J} 53$ recipients by conjugation, suggesting an intrinsic

5 resistance borne on the chromosome. The results suggest that, from the clinical point of view, if

6 we can succeed at curtailing the spread of ESBL-, AmpC-, or carbapenemase producing

7 enterobacteria, we may somewhat succeed at reducing the prevalence of antimicrobial resistance

8 among enterobacteria.

9 Our data should be interpreted considering potential limitations. Households were provided with cockroach collection kits and procedural guidelines. We are however unable to ascertain if

11 participants strictly adhered to aseptic collection guidelines. Nonetheless, the fact that all the CRe

12 isolates were the dominant colonies on culture suggest stable colonization. We have no data on

13 antibiotic use by household contacts and are thus unable to relate CRe colonization and antibiotic

14 consumption. Due to small sample size and provincial household concentration, our study is not

15 meant to be representative for the prevalence of AmpC-, ESBL-, or carbapenemase-producing

16 bacteria. It is noteworthy that the complimentary sampling of humans is biased since only humans

17 with corresponding positive household cockroach samples were examined. The study was

18 designed to investigate whether, within individual households, cockroaches and humans share

19 isolates of the same clone and antibiotic resistance determinants of public health concern

20 Conclusion. We report the disturbing colonization of household cockroaches with multidrug

21 resistant CTX-M-15 ESBL-producers, and extensively drug resistant NDM-1 and OXA-48

22 carbapenemase-positive Enterobacteriacaea. The findings highlight cockroaches as insects of

23 public health concern; and calls for regulations on their control especially in healthcare settings. 


\section{Acknowledgements}

2 The authors are grateful to Bill Wickstead (of Wickstead Lab, University of Nottingham School

3 of Life Sciences, UK) who assisted with some reagents for the project. We thank the following for

4 their laboratory support: Michael Olu-Taiwo (University of Ghana School of Biomedical and

5 Allied Health Sciences, Department of Medical Laboratory Sciences); Mary Magdalene Osei

6 (University of Ghana School of Biomedical and Allied Health Sciences, Medical Microbiology

7 department); Mr Thomas Dankwa (all of Korle-Bu Teaching Hospital Central Laboratory); and

8 Mr Seth Agyeman (Korle-Bu Teaching Hospital Central Laboratory). 


\section{References}

2 1. Rubin JE, Pitout JD. Extended-spectrum beta-lactamase, carbapenemase and AmpC 3 producing Enterobacteriaceae in companion animals. Vet Microbiol. 2014;170: 10-18. $4 \quad$ doi:10.1016/j.vetmic.2014.01.017

5 2. Bush K. Beta-lactamases. Ann N Y Acad Sci. 2013;1277: 84-90. doi:10.1111/nyas.12023

6 3. Cornaglia G, Giamarellou H, Rossolini GM. Metallo-??-lactamases: A last frontier for ??lactams? The Lancet Infectious Diseases. 2011. pp. 381-393. doi:10.1016/S1473-

9 4. Ćirković I, Pavlović L, Konstantinović N, Kostić K, Jovanović S, Djukić S. Phenotypic detection of beta-lactamases production in Enterobacteriaceae. Srp Arh Celok Lek. 2014;142: 457-463. doi:10.2298/SARH1408457C 3099(11)70056-1

5. Babic M, Hujer AM, Bonomo RA. What's new in antibiotic resistance? Focus on betalactamases. Drug Resist Updat. 2006;9: 142-156. doi:10.1016/j.drup.2006.05.005

6. Obeng-Nkrumah N, Twum-Danso K, Krogfelt KA, Newman MJ. High levels of extendedspectrum beta-lactamases in a major teaching hospital in Ghana: The need for regular monitoring and evaluation of antibiotic resistance. Am J Trop Med Hyg. 2013;89: 960-964. doi:10.4269/ajtmh.12-0642

7. Agyekum A, Fajardo-Lubián A, Ansong D, Partridge SR, Agbenyega T, Iredell JR. blaCTX-M-15 carried by IncF-type plasmids is the dominant ESBL gene in Escherichia coli and Klebsiella pneumoniae at a hospital in Ghana. Diagn Microbiol Infect Dis. 2016;84: 328-333. doi:10.1016/j.diagmicrobio.2015.12.010 
1 8. Hackman HK, Brown CA, Asmah RH, Badu CA, Amegashi G. Advances in Life Science and Technology. Advances in Life Science and Technology. International Institute for Science, Technology and Education (IISTE); 2011.

9. Potron A, Poirel L, Dortet L, Nordmann P. Characterisation of OXA-244, a chromosomallyencoded OXA-48-like $\beta$-lactamase from Escherichia coli. International Journal of Antimicrobial Agents. 2016. pp. 102-103. doi:10.1016/j.ijantimicag.2015.10.015

10. Oueslati S, Nordmann P, Poirel L. Heterogeneous hydrolytic features for OXA-48-like ??lactamases. J Antimicrob Chemother. 2014;70: 1059-1063. doi:10.1093/jac/dku524

9 11. Poirel L, Bonnin RA, Nordmann P. Genetic features of the widespread plasmid coding for the carbapenemase OXA-48. Antimicrob Agents Chemother. 2012;56: 559-562.

12. Hasan B, Drobni P, Drobni M, Alam M, Olsen B. Dissemination of NDM-1. Lancet Infect Dis. 2012;12: 99-100; author reply 101-2. doi:10.1016/S1473-3099(11)70333-4

13. Rahman M, Shukla SK, Prasad KN, Ovejero CM, Pati BK, Tripathi A, et al. Prevalence and molecular characterisation of New Delhi metallo- $\beta$ - lactamases NDM-1, NDM-5, NDM-6 and NDM-7 in multidrug-resistant Enterobacteriaceae from India. Int J Antimicrob Agents.

14. Page MGP. Cephalosporins in clinical development. Expert Opin Investig Drugs. 2004;13: 973-985. doi:10.1517/13543784.13.8.973 negative bacterial pathogens. International Journal of Medical Microbiology. 2010. pp. 371-379. doi:10.1016/j.ijmm.2010.04.005 
1 16. Davies J, Davies D. Origins and evolution of antibiotic resistance. Microbiol Mol Biol Rev. 2010;74: 417-33. doi:10.1128/MMBR.00016-10

17. Martinez JL. Environmental pollution by antibiotics and by antibiotic resistance determinants. Environmental Pollution. 2009. pp. 2893-2902. doi:10.1016/j.envpol.2009.05.051

18. Berendonk TU, Manaia CM, Merlin C, Fatta-Kassinos D, Cytryn E, Walsh F, et al. Tackling antibiotic resistance: the environmental framework. Nat Rev Microbiol. 2015;13: 310-317. doi:10.1038/nrmicro3439

19. Tetteh-Quarcoo PB, Donkor ES, Attah SK, Duedu KO, Afutu E, Boamah I, et al. Microbial carriage of cockroaches at a tertiary care hospital in ghana. Environmental health insights. 2013. pp. 59-66. doi:10.4137/EHI.S12820

20. Salehzadeh A, Tavacol P, Mahjub H. Bacterial, fungal and parasitic contamination of cockroaches in public hospitals of Hamadan, Iran. J Vector Borne Dis. 2007;44: 105-110.

21. Fotedar R, Shriniwas UB, Verma A. Cockroaches ( Blattella germanica) as carriers of microorganisms of medical importance in hospitals. Epidemiol Infect. 1991;107: 181-187. doi:10.1017/S0950268800048809

22. Kassiri H, Kassiri A, Kazemi S. Investigation on American cockroaches medically important bacteria in Khorramshahr hospital, Iran. Asian Pacific J Trop Dis. 2014;4: 201203. doi:10.1016/S2222-1808(14)60505-3

23. Fakoorziba MR, Shahriari-Namadi M, Moemenbellah-Fard MD, Hatam GR, Azizi K, Amin M, et al. Antibiotics susceptibility patterns of bacteria isolated from American and German cockroaches as potential vectors of microbial pathogens in hospitals. Asian Pacific J Trop 
Dis. 2014;4: S790-S794. doi:10.1016/S2222-1808(14)60728-3

2 24. Loucif L, Gacemi-Kirane D, Cherak Z, Chamlal N, Grainat N, Rolain JM. First report of German cockroaches (Blattella germanica) as reservoirs of CTX-M-15 extended-spectrum$\beta$-lactamase- and OXA-48 carbapenemase-producing Enterobacteriaceae in Batna University Hospital, Algeria. Antimicrob Agents Chemother. 2016;60: 6377-6380. doi:10.1128/AAC.00871-16

25. Ghana Statistical Service. Adentan Municipality: Population and housing census. District Analytical Report. 2014. doi:10.1016/0375-6505(95)90007-1

26. Sandelowski M. Combining qualitative and quantitative sampling, data collection, and analysis techniques in mixed-method studies. Res Nurs Health. 2000;23: 246-255. doi:10.1002/1098-240x(200006)23:3<246::aid-nur9>3.0.co;2-h

27. CLSI. M02-A12 Performance Standards for Antimicrobial Disk. Clsi. 2015.

28. EUCAST. European Commitee for Antibiotic Susceptibilty testing. In: EUCAST [Internet]. 2017 [cited 7 Nov 2017]. Available: http://www.eucast.org/clinical_breakpoints/

29. CLSI. M100S Performance Standards for Antimicrobial Susceptibility Testing. Clinical and Laboratory Standards Institute, Wayne, PA. 2016.

30. Pérez-Pérez FJ, Hanson ND. Detection of plasmid-mediated AmpC beta-lactamase genes in clinical isolates by using multiplex PCR. J Clin Microbiol. 2002;40: 2153-2162. doi:10.1128/JCM.40.6.2153

31. Azim A, Dwivedi M, Rao PB, Baronia a K, Singh RK, Prasad KN, et al. Epidemiology of bacterial colonization at intensive care unit admission with emphasis on extended-spectrum beta-lactamase- and metallo-beta-lactamase-producing Gram-negative bacteria--an Indian 
experience. J Med Microbiol. 2010;59: 955-60. doi:10.1099/jmm.0.018085-0

2 32. Wirth T, Falush D, Lan R, Colles F, Mensa P, Wieler LH, et al. Sex and virulence in Escherichia coli: an evolutionary perspective. Mol Microbiol. 2006;60: 1136-51. doi:10.1111/j.1365-2958.2006.05172.x

33. Francisco AP, Vaz C, Monteiro PT, Melo-Cristino J, Ramirez M, Carriço JA. PHYLOViZ: Phylogenetic inference and data visualization for sequence based typing methods. BMC Bioinformatics. 2012;13. doi:10.1186/1471-2105-13-87

34. Tamang MD, Nam HM, Jang GC, Kim SR, Chae MH, Jung SC, et al. Molecular characterization of extended-spectrum- $\beta$-lactamase- producing and plasmid-mediated AmpC $\beta$-lactamase-producing Escherichia coli isolated from stray dogs in South Korea.

35. Fotedar R, Banerjee U, Shriniwas. Vector potential of the German cockroach in dissemination of Pseudomonas aeruginosa. J Hosp Infect. 1993;23: 55-59.

36. Huijbers PMC, Graat EAM, Haenen APJ, van Santen MG, van Essen-Zandbergen A, doi:10.1016/0195-6701(93)90131-I Analysis of ESBL-Positive Escherichia coli Isolates from Animals and Humans from the 
1 38. Dierikx C, van der Goot J, Fabri T, van Essen-Zandbergen A, Smith H, Mevius D. Extended-spectrum- $\beta$-lactamase- and AmpC- $\beta$-lactamase-producing Escherichia coli in Dutch broilers and broiler farmers. J Antimicrob Chemother. 2013;68: 60-67. doi:10.1093/jac/dks349

39. Queenan AM, Bush K. Carbapenemases: the versatile beta-lactamases. Clin Microbiol Rev. 2007;20: 440-58. doi:10.1128/CMR.00001-07

40. Bush K. Bench-to-bedside review: The role of beta-lactamases in antibiotic-resistant Gramnegative infections. Crit Care. 2010;14: 224. doi:10.1186/cc8892

41. Bush K. Carbapenemases: Partners in crime. Journal of Global Antimicrobial Resistance. 2013. pp. 7-16. doi:10.1016/j.jgar.2013.01.005

42. Obeng-Nkrumah N, Labi A-K, Addison NO, Labi JEM, Awuah-Mensah G. Trends in paediatric and adult bloodstream infections at a Ghanaian referral hospital: a retrospective study. Ann Clin Microbiol Antimicrob. 2016;15: 49. doi:10.1186/s12941-016-0163-z

43. Obeng-Nkrumah N, Labi A-K, Acquah ME, Donkor ES. Bloodstream infections in patients with malignancies: implications for antibiotic treatment in a Ghanaian tertiary setting. BMC Res Notes. 2015;8: 742. doi:10.1186/s13104-015-1701-z

44. Labi A-K, Obeng-Nkrumah N, Addison NO, Donkor ES, Donkor ES. Salmonella blood stream infections in a tertiary care setting in Ghana. BMC Infect Dis. 2014;14: 3857. doi:10.1186/s12879-014-0697-7

45. Labi A-K, Obeng-Nkrumah N, Bjerrum S, Enweronu-Laryea C, Newman MJ. Neonatal bloodstream infections in a Ghanaian Tertiary Hospital: Are the current antibiotic recommendations adequate? BMC Infect Dis. 2016;16: 598. doi:10.1186/s12879-016$1913-4$ 


\section{Supporting information}

2 S1 Table. Oligonucleotides and PCR conditions used for amplification (internal primers included

3

for sequencing) 
bioRxiv preprint doi: https://doi.org/10.1101/357079; this version posted June 27,2018 . The copyright holder for this preprint (which was not certified by peer review) is the author/funder, who has granted bioRxiv a license to display the preprint in perpetuity. It is made available under aCC-BY 4.0 International license.

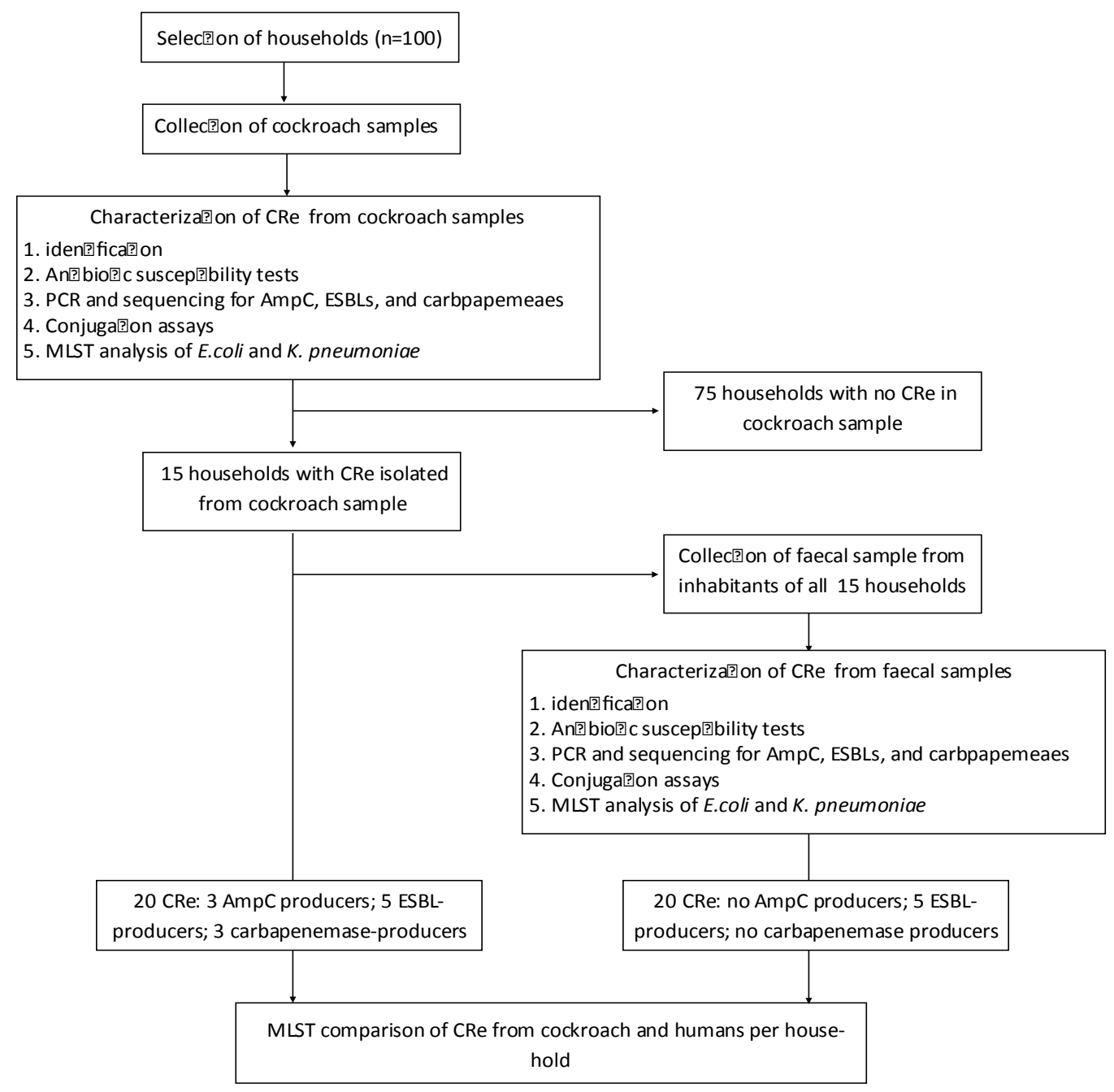

Fig. 1 
bioRxiv preprint doi: https://doi.org/10.1101/357079; this version posted June 27, 2018. The copyright holder for this preprint (which was not certified by peer review) is the author/funder, who has granted bioRxiv a license to display the preprint in perpetuity. It is made available under aCC-BY 4.0 International license.

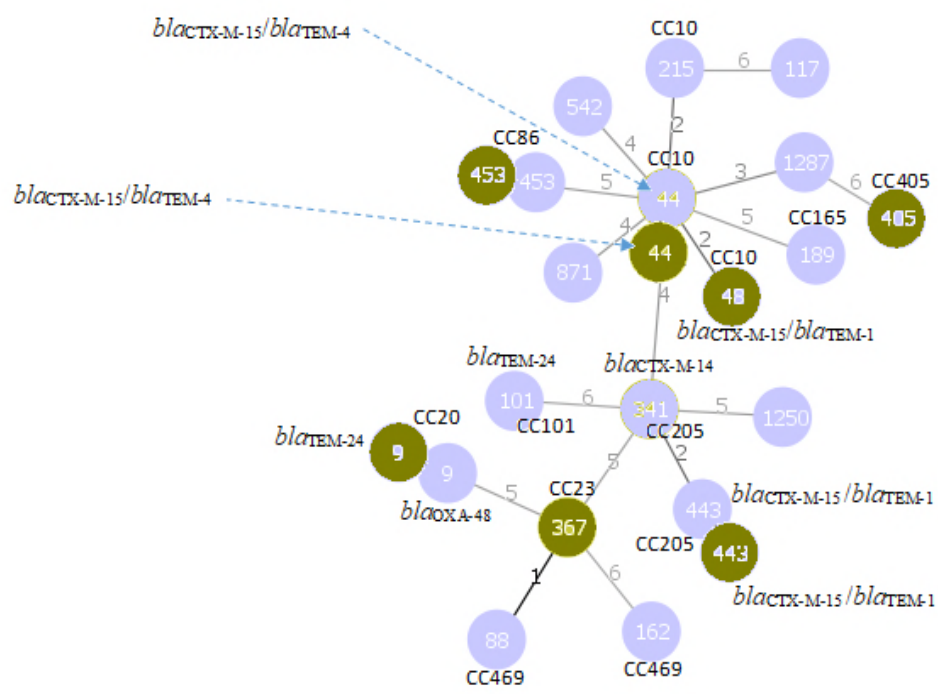

E. coli
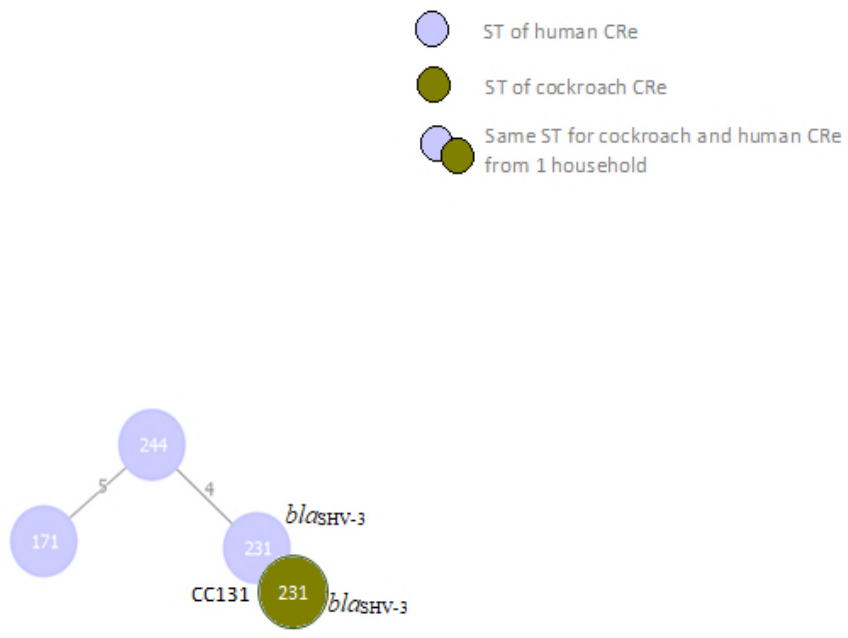

K. pneumoniae

Fig 3 